\title{
Development of a nursing care problems coping scale for male caregivers for people with dementia living at home
}

\author{
Midori Nishio ${ }^{1}$ and Mitsu Ono ${ }^{2}$ \\ ${ }^{I}$ Department of Health Sciences, Graduate School of Medical Sciences, Kyushu University, Japan \\ ${ }^{2}$ Department of Health Sciences, Faculty of Medical Sciences, Kyushu University, Japan
}

\begin{abstract}
Objective: The number of male caregivers has increased, but male caregivers face several problems that reduce their quality of life and psychological condition. This study focused on the coping problems of men who care for people with dementia at home. It aimed to develop a coping scale for male caregivers so that they can continue caring for people with dementia at home and improve their own quality of life. The study also aimed to verify the reliability and validity of the scale.

Patients/Material and Methods: The subjects were 759 men who care for people with dementia at home. The Care Problems Coping Scale consists of 21 questions based on elements of questions extracted from a pilot study. Additionally, subjects completed three self-administered questionnaires: the Japanese version of the Zarit Caregiver Burden Scale, the Depressive Symptoms and the Selfesteem Emotional Scale, and Rosenberg Self-Esteem Scale.

Results: There were 274 valid responses (36.1\% response rate). Regarding the answer distribution, each average value of the 21 items ranged from 1.56 to 2.68. The median answer distribution of the 21 items was $39(\mathrm{SD}=6.6)$. Five items had a ceiling effect, and two items had a floor effect. The scale stability was about $50 \%$, and Cronbach's $\alpha$ was 0.49 . There were significant correlations between the Care Problems Coping Scale and total scores of the Japanese version of the Zarit Caregiver Burden Scale, the Depressive Symptoms and Self-esteem Emotional Scale, and the Rosenberg Self-Esteem Scale. Conclusion: The answers provided on the Care Problems Coping Scale questionnaire indicated that male caregivers experience care problems. In terms of validity, there were significant correlations between the external questionnaires and 19 of the 21 items in this scale. This scale can therefore be used to measure problems with coping for male caregivers who care for people with dementia at home.
\end{abstract}

Key words: male caregivers, home care, dementia, care problems, coping

(J Rural Med 2015; 10(1): 34-42)

Received: 24 December 2014, Accepted: 5 March 2015

Correspondence: Midori Nishio, Doctoral Course, Kyushu University, 3-1-1 Maidashi, Higashi-ku, Fukuoka 812-8582, Japan

E-mail: 3MD12505K@s.kyushu-u.ac.jp

\section{Introduction}

In 2012, the Japanese population of older adults with dementia requiring nursing care was 4.62 million people ${ }^{1)}$. With a rapidly aging population and the extension of life expectancy ${ }^{2)}$, it is estimated that in $2025,25 \%$ of the population over the age of 65 will have dementia ${ }^{3}$.

The Ministry of Health, Labour and Welfare ${ }^{4)}$ stated that the aim of society should be that even if someone has dementia, they should be able to continue to live in a good environment to which are they accustomed and where they are respected.

In 2000, public nursing care insurance programs were implemented in Japan, but because there are so many different needs and the problems of family care vary, the care services that were provided were insufficient to meet these needs ${ }^{5,6)}$. In the case of people with dementia, the increased amount of care required because of the associated behavioral and psychological symptoms places a burden on the caregivers and worsens their psychological health ${ }^{7}$.

Nuclear families accounted for $6 \%$ of the total number of households in 2012 because of a change in family structure due to an increase in family size ${ }^{8)}$. The ability of people to care for family members has declined, social evolution of women has progressed because the role of women in society has changed and they are no longer the sole providers of long-term care, and many older adults have a smaller twogeneration family9). The number of male caregivers of people with dementia at home has quadrupled from $8.2 \%$ in 1981 to $32.2 \%$ in 2010 . Seventy-five percent of male caregivers of people with dementia are husbands, and $25 \%$ are sons $\mathbf{s}^{4}, 10$ ).

Male caregivers have been reported to have health problems and social issues ${ }^{9)}$, they suffer from depression ${ }^{11}$, tension ${ }^{12)}$, and dissatisfaction ${ }^{13)}$, and their needs are not represented $\left.{ }^{9}{ }^{14}, 15\right)$. Male caregivers do not seek counseling or support from friends or other people ${ }^{16)}$, and they can be easily isolated from the area in which they live ${ }^{17}$. They are 
often so devoted to the care they provide that they cannot work or pursue personal interests ${ }^{18)}$. The problems that male caregivers are faced with can affect each other, thereby reducing quality of life (QOL) and affecting psychological conditions ${ }^{19}$. Therefore, it is important to address the fact that male caregivers experience several care problems that are not being effectively dealt with.

In this study, we focused on coping problems experienced by male caregivers of people with dementia living at home. The Care Problems Coping Scale has already been used for family caregivers ${ }^{18)}$. However, much of the development of this scale has included female caregivers. To prevent burnout in male caregivers who do not seek help even when they have a problem, it is necessary to evaluate the development of a coping scale of care problems, from the perspective of nursing based on the characteristics of men who care for people with dementia at home. Where care is required on a daily basis, family support is essential for the person with dementia to continue living at home. Nurses who can provide the necessary care for the caregivers, to support them in dealing with long-term care problems, are required.

The purpose of this study was to verify the reliability and validity of a scale that examines the care problems of male caregivers of people with dementia living at home. The main aim of this was to ensure that men can continue to care for people with dementia at home and to improve the QOL of these caregivers.

\section{Patient and Methods}

The subjects were 759 male caregivers recruited from four places: (1) Fukuoka University Hospital Department of Psychiatry Medicine and Department of Neurology caregivers of outpatients with dementia, (2) caregivers of inpatients at the Special Hospital for Dementia, (3) members of the Male Caregivers Association nationwide, and (4) members of associations of dementia patient's families nationwide. The subjects completed a self-administered questionnaire. The study period was September 2013-January 2014.

\section{Procedure}

Development of the Care Problems Coping Scale was based on previous studies ${ }^{12.14,15)}$, and on the coping process described in previous studies using the Sakata Coping Scale (SCS). The SCS is the most commonly used scale in prior research. First, we examined coping with care problems. Second, we surveyed nine men who care for people with dementia living at home.

The survey interview included questions such as, "When do you experience problems with providing care at home?" and "What do you think about this, and how do you deal with it?" Analysis of the interview results included creating of a verbatim record by three experts in dementia research, to ensure the intended meaning of the terminology remained clear $^{20-23)}$. We also examined the results of previous studies with the SCS. The SCS was not apply coping from previous research and interviews. I added to not apply SCS. Not apply is "I think that it is known as shameful" and "Blame myself that cannot be good nursing care." A Care Problems Coping Scale was developed with 21 items in total. There were three choices for each response: "I mostly disagree," "I somewhat agree," and "I agree," This scale has achieved face validity and was discussed with three experts ${ }^{20)}$.

\section{Topics}

Relevant questions to be asked are related to: age, presence or absence of a housemate, household composition, relationship with the caregiver, employment situation, economic condition subjective judgment of health state, and nursing care time.

\section{Scale to examine validity}

We used the following scales to examine the validity of our scale: the Japanese version of the Zarit Caregiver Burden Scale $(\mathrm{J}-\mathrm{ZBI})^{24)}$,the Depressive Symptoms and Self-esteem Emotional Scale (SDS ${ }^{25)}$, and the Japanese version of the Rosenberg Self-Esteem Scale (RSES-J) ${ }^{26,27)}$. These scales relate to Pearlin's stress process model of family caregivers of people with dementia ${ }^{28)}$. The Pearlin model postulates that coping with the burden of a care situation is perceived subjectively. As a result of the conflict in the performance of care, self-esteem and self-control are lowered. If the burden is decreased for caregivers, they may experience physical and psychological changes affecting their symptoms of depression ${ }^{18)}$.

J-ZBI: This scale consists of 22 items. It is a care burden scale that was translated into Japanese by Arai et al. ${ }^{24)}$. Its reliability and validity have been verified, and it has been used in many previous studies in Japan. Its main focus is the burden arising from care, the burden caused to begin care, and care burden overall. There are five response choices: "never," "rarely," "sometimes," "quite often," and "nearly always." The maximum score is out of 84 points.

SDS: This scale consists of 20 items. It is also used to assess symptoms of depression and correlates with HAM$\mathrm{D}$ depression diagnostic criteria. There are four answer options: "infrequently," "sometimes," "often," and" almost always." The maximum total score is 80 points. Scores in the 20-40 range indicate no or slight depression, scores in the 40-49 range indicate mild depression, and scores over 50 indicate moderate depression.

RSES-J: This scale consists of 10 items. It is a measure that has been used most often in foreign countries. The re- 
liability and validity of the Japanese version were established in 2007. It has four answer options: "strongly agree," "agree," "disagree," and“"strongly disagree." The maximum total score is 40 points.

\section{Information about the care receiver}

Relevant questions to be asked are related to: age, diagnosis of dementia, certification of long-term care need, and degree of autonomy criteria for dementia in older adults ${ }^{29)}$.

\section{Statistical analyses (Care Problems Coping Scale)}

We performed an item analysis to examine the answer distribution and assess for ceiling and floor effects based on the mean and standard deviation. We determined reliability using Cronbach's $\alpha$ coefficient. We used other measures adopted as external criteria to determine validity. All statistical analyses were performed using the Japanese version of SPSS22.0 for Windows. The level of statistical significance was set at .05 (two-tailed).

\section{Ethical approval}

We obtained ethical approval for this study from the ethics committee (approval code: 13-7-07) and the study conforms to the provisions of the Declaration of Helsinki in 1995 (as revised in Tokyo in 2004). Consent was obtained from hospitals, a care facility, and the Men's Caregiver and Family Association. The purpose of the study was explained verbally and in writing to the relevant parties. Subjects were informed that their information and data would be treated confidentially. Subjects gave their consent by returning completed questionnaires.

\section{Results}

\section{Demographic data of the subjects}

The mean subject age was 69.9 (SD 11.1) years. Eightynine $(32.4 \%)$ of the subjects were $70-79$ years old, 78 (27.6\%) were 60-69 years old, and 54 (19.7\%) were $80-89$ years old. Regarding presence or absence of a housemate, $91(33.2 \%)$ indicated they had a housemate (other than the caregiver), and 183 (65.7\%) indicated they did not. In terms of household composition, $131(47.8 \%)$ were single families, $80(29.2 \%)$ were three-generation families, and $55(20.1 \%)$ were two-generation families. The patient's relationship with the caregiver was indicated as wife of the caregiver by 176 subjects (62.4\%), patient of the caregiver by 105 subjects (37.2\%), and another relative by 1 subject ( $0.3 \%)$.

Of the subjects, 99 (36.2\%) were employed, 37 (37.4\%) were farmers, 28 (28.3\%) were company employees, and 22 (22.2\%) worked in a family-operated business. For economic conditions, 216 (78.8\%) reported that their economic situ- ation was not a hindrance to life, and $56(20.4 \%)$ reported that their economic situation was a hindrance to life. For subjective judgment of health state, 162 (59.1\%) reported themselves as healthy, and $82(29.9 \%)$ reported themselves as unhealthy. The mean time of nursing care provided was 11.6 (SD 8.4) hours. One hundred and thirteen subjects $(67.3 \%)$ provided $1-9$ hours of nursing care, $48(17.5 \%)$ provided 20 hours or more, and 47 (17.1\%) provided 10-19 hours. The J-ZBI mean score was 32.8 (SD 17.4), and the SDS mean score was 43.3 (SD 9.6). Results from a threestage evaluation for the SDS for the showed that 95 (34.7\%) subjects were not depressed or only slightly depressed, 89 $(32.5 \%)$ were mildly depressed, and $80(29.2 \%)$ were moderately depressed. The RSES-J mean score was 17.62 (SD 4.4). These data are shown in Table 1.

\section{Overview of the people with dementia}

The mean age of the people with dementia was 78.3 (SD 9.6) years. Among them, 94 (33.2\%) were $80-89$ years, 89 $(31.2 \%)$ were $70-79$ years, and $48(16.9 \%)$ were $60-69$ years. Regarding the diagnosis of dementia, 239 (84.6\%) had the Alzheimer's type, 26 (9.2\%) had the cerebrovascular type, and $14(4.8 \%)$ had frontemporal lobar degeneration. In terms of certification of long-term care need, $60(21.2 \%)$ had a care need rating of $1,53(18.7 \%)$ had a care need rating of 3 , and $45(15.9 \%)$ had a care need rating of 3 (Table 2).

\section{Day-to-day functioning and degree of autonomy criteria for older adults with dementia}

Sixty-three $(22.3 \%)$ patients with dementia were rated as "IV: Demonstrated many difficulties with communication and symptoms and behaviors that interfered with daily life. Need continuous nursing care." Fifty-six (20.0\%) were rated as "I: Have some dementia, but their home, daily life, and social life are almost independent." Forty-nine (17.4\%) were rated as "III: Have some difficulties with communication and symptoms and behaviors that interfered with daily life. Need nursing care." Thirty-eight (13.5\%) were rated as "II: Demonstrated a few difficulties with communication and symptoms and behaviors that interfered with daily life. Can be self-supporting if someone is there to guide them." Thirty-one (11.0\%) were rated as "II b: Same state as II but also in the home" (Table 3).

Answer distribution and reliability of Care Problems Coping Scale

The mean scores for the items on the Care Problems Coping Scale ranged from 1.56 to 2.68. The ceiling and floor effects were calculated from the mean and average score.

For ceiling effects, the mean score for "Nursing care is given to their own problem" was 2.38 (SD 0.71). The mean 
Table 1 Subject contents

\begin{tabular}{|c|c|c|}
\hline \multicolumn{2}{|c|}{ Variable } & \multirow{2}{*}{$\frac{\text { Results (\%) }}{69.9 \text { SD } 11.1}$} \\
\hline Age & Mean age & \\
\hline & 20-29 years & $1(0.3)$ \\
\hline & $30-39$ years & $2(0.7)$ \\
\hline & $40-49$ years & $20(7.2)$ \\
\hline & $50-59$ years & $21(7.6)$ \\
\hline & $60-69$ years & $78(27.6)$ \\
\hline & 70-79 years & $89(32.4)$ \\
\hline & $80-89$ years & $54(19.7)$ \\
\hline & Over 90 years & $4(1.4)$ \\
\hline & No answer & $5(1.8)$ \\
\hline \multirow[t]{2}{*}{ Presence or absence of housemate } & Yes & $91(34.3)$ \\
\hline & No & $183(65.7)$ \\
\hline \multirow[t]{5}{*}{ Household composition } & Single family & $131(47.8)$ \\
\hline & Two-generation family. & $55(20.1)$ \\
\hline & Three-generation family & $80(29.2)$ \\
\hline & Other & $5(1.5)$ \\
\hline & No answer & $3(1.0)$ \\
\hline \multirow[t]{3}{*}{ Relationship with the caregiver } & Parent & $105(37.2)$ \\
\hline & Wife & $176(62.4)$ \\
\hline & relatives & $1(0.3)$ \\
\hline \multirow[t]{6}{*}{ Situation of employment } & relatives & $99(36.2)$ \\
\hline & Farmer & $37(37.4)$ \\
\hline & Company employee & $28(28.3)$ \\
\hline & Family-operated business & $22(22.2)$ \\
\hline & Director & $12(12.1)$ \\
\hline & Unemployed person & $175(63.8)$ \\
\hline \multirow[t]{3}{*}{ Economic conditions } & No hindrance to life & $216(78.8)$ \\
\hline & Hindrance to life & $56(20.4)$ \\
\hline & Other & $2(0.7)$ \\
\hline \multirow[t]{3}{*}{ Subjective judgment of health state } & Healthy & $162(59.1)$ \\
\hline & Not healthy & $82(29.9)$ \\
\hline & No answer & $30(11.0)$ \\
\hline \multirow[t]{5}{*}{ Nursing care time } & Mean time & 11.6 SD 8.4 \\
\hline & $1-9$ hours & $113(67.3)$ \\
\hline & 10-19 hours & $47(17.1)$ \\
\hline & Over 20 hours & $48(17.5)$ \\
\hline & No answer & $66(24.0)$ \\
\hline $\mathrm{J}-\mathrm{ZBI}$ & Mean point score (SD) & 32.8 SD 17.4 \\
\hline \multirow[t]{4}{*}{ SDS } & Mean point score (SD) & $43.3 \mathrm{SD} 9.6$ \\
\hline & No or slight depression & $95(34.7)$ \\
\hline & Mild depression & $89(32.5)$ \\
\hline & Moderate depression & $80(29.2)$ \\
\hline RSES-J & Mean point score (SD) & $17.6 \mathrm{SD} 4.4$ \\
\hline
\end{tabular}

score for "I don't give a damn to nursing care." was 2.62 (SD 0.59). The mean score for "I do not see. And I go away from the scene of the problem" was 2.61 (SD 0.60). The mean score for "I became emotional or destroyed things" was 2.36 (SD 0.65). The mean score for "Blame myself that cannot be good nursing care.” was 2.28 (SD 0.75).
Regarding floor effects, the mean score for "Wait until I can take care of them well" was 1.60 (SD 0.66). The mean score for "I ask for help from neighbors and family and relatives" was 1 (SD 0.64) (Table 4). We observed normal distributions for the whole Care Problems Coping Scale. The median was 39 , the mode was 40 , and the average was 37.97 
Table 2 Overview of the persons with dementia

\begin{tabular}{|c|c|c|}
\hline \multicolumn{2}{|l|}{ Variable } & Results (\%) \\
\hline Age & Mean & 78.3 SD 9.6 \\
\hline & $50-59$ years & $5(1.7)$ \\
\hline & $60-69$ years & $48(16.9)$ \\
\hline & $70-79$ years & $89(31.2)$ \\
\hline & $80-89$ years & $94(33.2)$ \\
\hline & Over 90 years & $34(12.0)$ \\
\hline & No answer & $12(4.2)$ \\
\hline \multirow[t]{4}{*}{ Diagnosis of dementia } & Alzheimer's type & $239(84.6)$ \\
\hline & Frontotemporal lobar degeneration & $26(9.2)$ \\
\hline & Cerebrovascular type & $14(4.8)$ \\
\hline & Pick's disease type & $3(1.0)$ \\
\hline \multirow[t]{8}{*}{ Situation of certification of long-term care need } & Care support 1 & $9(2.7)$ \\
\hline & Care support 2 & $11(3.3)$ \\
\hline & Care need 1 & $60(21.2)$ \\
\hline & Care need 2 & $45(15.9)$ \\
\hline & Care need 3 & $37(13.1)$ \\
\hline & Care need 4 & $39(13.8)$ \\
\hline & Care need 5 & $53(18.7)$ \\
\hline & Did not apply & $28(9.9)$ \\
\hline
\end{tabular}

Care support is a less intensive level of support required than care need. The numbers refer to increasing levels of care required.

Table 3 Day-to-day functioning and degree of autonomy criteria for older adults with dementia

\begin{tabular}{|c|c|c|}
\hline & Variable & Results $(\%)$ \\
\hline I & Have some dementia, but home, daily, and social life are almost independent. & $56(20.0)$ \\
\hline II & $\begin{array}{l}\text { Demonstrated a few difficulties with communication and symptoms and behaviors that interfered with daily life. } \\
\text { Can be self-supporting if someone is there to guide them. }\end{array}$ & $38(13.5)$ \\
\hline II a & Same state as II but also out of home. & $8(2.8)$ \\
\hline II $b$ & Same state as II but also in the home. & $31(11.0)$ \\
\hline III & $\begin{array}{l}\text { Sometimes demonstrated difficulties with communication and symptoms and behaviors that interfere with daily life. } \\
\text { Need nursing care. }\end{array}$ & $49(17.4)$ \\
\hline III a & Same state as III but also in the day. & $16(5.7)$ \\
\hline III $b$ & Same state as III but also in the night. & $3(1.1)$ \\
\hline IV & $\begin{array}{l}\text { Frequently demonstrated difficulties with communication and symptoms and behaviors that interfere with daily life. } \\
\text { Need continuous nursing care. }\end{array}$ & $63(22.3)$ \\
\hline M & Have notable mental symptoms and problematic action or serious physical disease and need specialized medical care. & $18(6.4)$ \\
\hline
\end{tabular}

(SD 6.6). The minimum value was 1 , and the maximum value was 61 .

\section{Reliability}

Cronbach's $\alpha$ was used to measure the internal consistency of the Care Problems Coping Scale; we observed an overall Cronbach's $\alpha$ of 0.49 .

\section{Validity: criterion-related validity}

There were significant correlations between 18 items of the Care Problems Coping Scale and the J-ZBI $(r=0.12-$
0.41). There were significant correlations between 10 items of the Care Problems Coping Scale and the SDS $(r=0.14$ 0.37). There were significant correlations for 8 items of the Care Problems Coping Scale with the three-stage evaluation for the SDS Three-stage Evaluation $(r=0.13-0.34)$. We found significant correlations between 7 items of the Care Problems Coping Scale and the RSES-J ( $r=0.18-0.29$ ). There were also significant correlations between the total points of the Care Problems Coping Scale and the external criteria $(r=0.18-0.33)$ (Table 5). 
Table 4 Distribution, reliability, and ceiling and floor effects

\begin{tabular}{|c|c|c|c|c|}
\hline Care Problems Coping Scale Item & Average & SD & Ceiling effect & Floor effect \\
\hline 1 I plan for when I perform nursing care. & 1.86 & 0.74 & 2.6 & 1.2 \\
\hline 2 I collect information to help with nursing care. & 2.09 & 0.71 & 2.8 & 1.4 \\
\hline 3 When nursing care is not successful, I think about the cause. & 1.90 & 0.70 & 2.6 & 1.3 \\
\hline 4 I do my best nursing care. & 2.26 & 0.70 & 3.0 & 1.6 \\
\hline 5 Nursing care is given to their own problem. & 2.38 & 0.71 & $3.1 \circ$ & 1.7 \\
\hline 6 I think that one can learn from the experience of caring. & 2.16 & 0.68 & 2.8 & 1.5 \\
\hline 7 I will not think deeply about nursing care. & 2.27 & 0.71 & 2.9 & 1.0 \\
\hline 8 I am not thought deeply what happens future of nursing situation. & 2.08 & 0.74 & 2.8 & 1.2 \\
\hline 9 I have resigned myself to thinking that nursing care is unavoidable. & 1.89 & 0.79 & 2.7 & 1.3 \\
\hline 10 I don't give dawn to nursing care. & 2.62 & 0.59 & $3.2 \circ$ & 2.0 \\
\hline 11 I think hopeful that it is overcame problem. & 1.71 & 0.70 & 2.4 & 1.0 \\
\hline 12 I wait until I can good nursing care. & 1.60 & 0.66 & 2.3 & $0.9 \bullet$ \\
\hline $\begin{array}{l}13 \text { It is a heavy burden to provide nursing care, so I obtain the support of family and } \\
\text { the people around me. }\end{array}$ & 1.69 & 0.70 & 2.4 & 1.0 \\
\hline 14 I ask for help from neighbors, family, and/or relatives. & 1.56 & 0.64 & 2.2 & $0.9 \bullet$ \\
\hline 15 Provide distractions and diversions. & 2.04 & 0.72 & 2.8 & 1.3 \\
\hline 16 I encouraging myself while nursing care. & 1.95 & 0.75 & 2.7 & 1.2 \\
\hline 17 I do not see. And I go away from the scene of the problem. & 2.61 & 0.60 & $3.2 \circ$ & 2.0 \\
\hline 18 I became emotional or destroyed things. & 2.36 & 0.65 & $3.0 \circ$ & 1.8 \\
\hline 19 I think that it is not my responsibility. & 2.46 & 0.69 & 2.3 & 1.8 \\
\hline 20 I think that it is seen as shameful. & 2.68 & 0.62 & 1.9 & 2.0 \\
\hline 21 Blame myself that can not be good nursing care. & 2.28 & 0.75 & $3.0 \circ$ & 1.5 \\
\hline
\end{tabular}

$\circ=$ Ceiling effect (average $+\mathrm{SD}>3$ ), $\bullet=$ Floor effect (average $-\mathrm{SD}<1$ ).

Table 5 Criterion-related items

\begin{tabular}{|c|c|c|c|c|}
\hline Care Problems Coping Scale Item & $\mathrm{J}-\mathrm{ZBI}$ & SDS & $\begin{array}{l}\text { SDS three-stage } \\
\text { evaluation }\end{array}$ & RSES-J \\
\hline 1 I plan for when I perform nursing care. & $0.21 * *$ & 0.07 & 0.05 & 0.01 \\
\hline 2 I collect information to help with nursing care. & $0.20 * *$ & -0.01 & -0.06 & 0.07 \\
\hline 3 When nursing care is not successful, I think about the cause. & $0.19 * *$ & 0.01 & -0.02 & 0.05 \\
\hline 4 I do my best nursing care. & $0.37 * *$ & $0.14 *$ & 0.11 & 0.00 \\
\hline 5 Nursing care is given to their own problem. & $0.15^{*}$ & -0.05 & -0.07 & 0.01 \\
\hline 6 I think that one can learn from the experience of caring. & $0.14 *$ & $-0.17 * *$ & $-0.23 * *$ & 0.08 \\
\hline 7 I will not think deeply about nursing care. & $-0.15 *$ & 0.02 & 0.05 & -0.01 \\
\hline 8 I am not thought deeply what happens future of nursing situation. & $-0.23 * *$ & -0.01 & 0.03 & 0.09 \\
\hline 9 I have resigned myself to thinking that nursing care is unavoidable. & $-0.34 * *$ & $-0.14 *$ & -0.10 & $0.16^{* *}$ \\
\hline 10 I don't give dawn to nursing care. & $-0.38 * *$ & $-0.37 * *$ & $-0.34 * *$ & $0.29 * *$ \\
\hline 11 I think hopeful that it is overcame problem. & 0.06 & 0.00 & -0.01 & -0.02 \\
\hline 12 I wait until I can good nursing care. & 0.08 & -0.01 & -0.02 & -0.01 \\
\hline $\begin{array}{l}13 \text { It is a heavy burden to provide nursing care, so I obtain the support of family and } \\
\text { the people around me. }\end{array}$ & $0.18^{* *}$ & 0.11 & 0.08 & -0.03 \\
\hline 14 I ask for help from neighbors, family, and/or relatives. & $0.12 *$ & -0.02 & -0.04 & 0.02 \\
\hline 15 Provide distractions and diversions. & 0.08 & $-0.24 * *$ & $-0.28 * *$ & $0.18^{* *}$ \\
\hline 16 I encouraging myself while nursing care. & $-0.41 * *$ & $-0.20 * *$ & $-0.13 *$ & 0.00 \\
\hline 17 I do not see. And I go away from the scene of the problem. & $-0.22 * *$ & $-0.25 * *$ & $-0.23 * *$ & $0.20 * *$ \\
\hline 18 I became emotional or destroyed things. & $-0.34 * *$ & $-0.22 * *$ & $-0.15^{*}$ & $0.17 * *$ \\
\hline 19 I think that it is not my responsibility. & $-0.18^{* *}$ & -0.07 & -0.02 & 0.09 \\
\hline 20 I think that it is seen as shameful. & $-0.23 * *$ & $-0.34 * *$ & $-0.31 * *$ & $0.23 * *$ \\
\hline 21 Blame myself that can not be good nursing care. & $-0.34 * *$ & $-0.32 * *$ & $-0.30 * *$ & $0.15^{*}$ \\
\hline Total points & $-0.18 * *$ & $-0.33 * *$ & $-0.33 * *$ & $0.29 * *$ \\
\hline
\end{tabular}

The test statistic is Pearson's $r$ correlation coefficient. $* * \mathrm{p}<0.01,{ }^{*} \mathrm{p}<0.05$. 


\section{Discussion}

We developed the Care Problems Coping Scale for male caregivers to help them to continue caring for people with dementia at home. We aimed to improve caregiver QOL and to verify the reliability and validity of this scale. Another scale, the WAKE, has been developed that looks at the coping style of female caregiver ${ }^{18)}$. Many caregivers who have unhappy lives as caregivers are male. In nursing care, there is male-specific coping ${ }^{30,31)}$. Studies have demonstrated that care coping problems differ by gender ${ }^{32}$. However, many of the subjects in these studies are female caregivers. There do not appear to be any studies that have focused on the problems of male caregivers. Even if there is a care burden, coping abilities can alter responses to stress ${ }^{33)}$. Thus, being aware of what care problems exist allows for interventions to be created or for coping strategies to be provided to help caregivers. The significance of this study is that it has revealed care problems specifically in men.

\section{Consideration of scale items}

Men experience care-related coping problems. We performed a literature review and interviewed men who care for people with dementia at home. We examined the items that categorize the contents related to problems of coping with caregiving to illustrate these problems in male caregiv$\mathrm{ers}^{34)}$. The contents of our scale and its 21 items have been discussed among experienced researchers; the scale was discussed by three experts and was found to have face validity.

Analysis of the distribution of the answers confirmed that there were floor and ceiling effects. The ceiling effects were observed for the following items: "Nursing care is given to their own problem," "I don't give dawn to nursing care," "I do not see. And I go away from the scene of the problem," "I became emotional or destroyed things," and "Blame myself that cannot be good nursing care." Men found value in nursing care, and male caregivers were willing to tackle the challenge of nursing care. This is the reason coping problems of men preforming nursing care ware considered. The subjects revealed a "so-what" attitude in that they did not care if there was embarrassment about being a caregiver. They were defiant in their attitude, and they worked around the problem and the emotional aspect of it. Thus, these items were adopted.

Floor effects were observed for the following items: "Wait until I can take care of them well" and "I ask for help from neighbors and family and relatives." However, these items revealed that if the caregiver cannot ask other people for help with care, he will have conflict between nursing care and improving everyday life. The items showed a normal distribution, and the results were observed to exhibit no answer bias. Therefore, the items were adopted. Because the answers were dispersed evenly, the male caregivers were considered to have revealed problems associated with coping as caregivers.

\section{Reliability}

Reliability refers to internal consistency; it is important that the same results can be obtained when an experiment is repeated. It is an index representing the stability of the scale $^{35)}$. The stability of this scale was approximately $50 \%$ in light of the Cronbach's $\alpha$ coefficient of 0.49 .

There were nine items with a normal distribution that related mostly to the family caregivers' coping style items of the WAKE Scale ${ }^{18)}$. Family caregiver coping style items in the WAKE Scale over three-dimensions: problem-solving, cognitive transformation type, and avoid or emotional type. Regarding development of the Care Problems Coping Scale items that matched the problem-solving dimension, there were five items, "I collect information to help care," "I provide distractions and diversions," "I think that one can learn from the experience of caring," "I think hopeful that it is overcame problem," and "It is a heavy burden to provide care, so I obtain the support of family and the people around me."

Regarding development of the Care Problems Coping Scale items that matched the cognitive transformation type, there were three items, "I have resigned myself to thinking that care is unavoidable," "I do my best nursing care," and "I encouraging myself while nursing care ." Regarding Care Problems Coping Scale items that matched the avoid or emotional type, there was one item, "I am not thought deeply what happens future of nursing situation."

There were five items that had a normal distribution, and they mostly consisted of contents of the dementia caregivers' coping strategies of Suganuma", namely: "positive acceptance of the nursing role," "recreation," "private support pursuit," and "public support pursuit." Regarding the Care Problems Coping Scale items that matched "positive acceptance of the nursing role," there were five items, "I plan for when I perform nursing care," "When nursing care is not successful, I think about the cause," "I will not think deeply about the level of care," "I think that it is not my responsibility," and "I think that it is known as shameful." Therefore, the scale was considered reliable because 14 items were found to have a normal distribution.

\section{Validity}

Validity is important because it determines whether a measurement tool or scale actually measures the concept and phenomenon that it is supposed to measure ${ }^{35}$. Care problems have achieved face validity as determined by experts at the time of item creation. We examined the criterion-related validity of our scale using empirical data. Criterion-related validity is a useful measure of correlations when the exter- 
nal reference is high.

There were four items that were significantly correlated between 19 items of the Care Problems Coping Scale and the J-ZBI, SDS, and RSES-J. In particular, these items were: "I don't give dawn to nursing care," "I do not see. And I go away from the scene of the problem," "I became emotional or destroyed things," and "I think that it is seen as shameful." These four items demonstrated care problems and were consistent with negative evaluation, which is a feature that affects depression and care burden of caregivers ${ }^{6}$. Therefore, we considered these items to be a feature of care problems for male caregivers.

A higher total score for the Care Problems Coping Scale was significantly correlated with all of the external references. It is inferred from these results that the Care Problems Coping Scale measures the coping abilities of men caring for people with dementia at home. Furthermore, we believe that this scale has a certain degree of validity.

\section{Feasibility and significance}

The National Livelihood Survey of 2010 $0^{36)}$ showed that the proportion of men as the "principal caregiver" was $32.8 \%$. The population of Japan is aging; in 2014, it was estimated that, on average, women live approximately 7 years longer than men. Furthermore, the number of nuclear family households is increasing, while the number of threegeneration households is decreasing ${ }^{4}$. We believe that when women suffer from poor health, their sons and husbands become responsible for nursing care.

In Japanese society, men are encouraged to not display emotions ${ }^{37}$. By focusing on coping styles of men, we may be able to predict care burden and its effects on self-esteem and the onset of depression. To promote home care, family support is essential. It is meaningful, and we should consider ways of providing family support.

The significance of this study is that we developed a Care Problems Coping Scale for male caregivers. This scale may allow us to develop programs to support men who are caregivers at home and to consider effective interventions. Future research could explore, in a clinical setting, ways of providing nursing support specific to men who provide care at home.

\section{Limitations and challenges}

One limitation of this study is the regional characteristics of the subjects; this study was based on a performed throughout across $\mathrm{Japan}^{38}$. However, those belonging to organizations such as the Family Association accounted for about 50\% of the sample. Inclusion of members of the Family Association means family members may share information and concerns with each other and may have encouraged each other ${ }^{39}$, 40). Furthermore, it is believed that for men, there is no outlet for their troubles. Men do not always want to receive support

Another limitation is that the average age of the subjects was 69.9 years; these were all older adults who may respond differently than younger adults. Additionally, $60 \%$ of the subjects were not working. According to data concerning employment status from research performed in 200740), caregivers had to leave or change their jobs because of an increased need for care at home. Future investigations are required to establish whether differences such as the presence or absence of work affect the experiences of caregiving in different subjects. We wanted to ensure the stability of the Care Problems Coping Scale, and we selected items that overlapped with other studies so that our scale could be used to easily evaluate care problems of male caregivers.

\section{Conclusion}

We developed a scale to measure problems with coping for male caregivers who care for people with dementia at home, and we demonstrated the validity and reliability of the scale.

\section{Acknowledgments}

We sincerely thank the doctors who cooperated with Fukuoka University Hospital, Associate Professor Hiromi Kimura of Saga University, and Professor Masahiro Nakano of Junshin Gakuen University. This study was supported by the 2013 first semester home care subsidy of Yuubi Memorial Goods Research Funding.

\section{References}

1. Department of Psychiatry, University of Tsukuba Dementia prevalence in the urban area and correspondence to life functional disorder of dementia. Available from: http://www. tsukuba-psychiatry.com [accessed 14 August 2014].

2. Tanigawa D, Misu S, Sawa R, et al. Cross-sectional relationships between depression and psychological elements of pain for elderly people requiring long-term care. Psychogeriatrics 2014; 2: 177-184.

3. Kiyohara Y. Advances in aging and health research. Japan Foundation for Aging and Health 2013; 1: 25-34 (in Japanese, abstract in English).

4. 2013/2014 Journal of health and welfare statistics. Health, Labour and Welfare Statistics Association 2014.

5. Maekubo M, Okamoto K, Hashimoto M. The effect on family function of home caregivers nursing frail elderly. KIBI International University 2007; 12: 31-38 (in Japanese, abstract in English).

6. Aonuma M, Sato M. Caregiving appraisal and coping strategies for family caregivers of persons with dementia. Japanese Journal of Nursing Research 2011; 45: 41-49 (in Japanese, abstract in English). 
7. Meiland FJ, Kat MG, van Tilburg W, et al. The emotional impact of psychiatric symptoms in dementia on partner caregivers: do caregiver, patient, and situation characteristics make a difference? Alzheimer Dis Assoc Disord 2005; 19: 195-201. [Medline] [CrossRef]

8. 2013/2014 Journal of health statistics. Health, Labour and Welfare Statistics Association 2014; Tokyo.

9. Nagai K, Hori Y, Hoshino J, et al. Subjective physical and mental health characteristics of male family caregivers. Nippon Koshu Eisei Zasshi 2011; 58: 606-616 (in Japanese, abstract in English). [Medline]

10. Nakamura M, Nagai M, Matsubara M. A study of factors that promote "ability for better living" for elderly male caregivers. Nippon Ronen Igakkai Zasshi Japanese Journal of Geriatrics 2011; 16: 104-110 (in Japanese, abstract in English).

11. Ashley NR, Kleinpeter CH. Gender differences in coping strategies of spousal dementia caregivers. J Hum Behav Soc Environ 2002; 6: 29-46. [CrossRef]

12. Papastavrou E, Tsangari H, Kalokerinou A, et al. Gender issues in caring for demented relatives. Health Sci J 2009; 3 : 41-53.

13. Tsudome M. Otokono kaigowo ikiru anatae. To you to live the care of man. Creates Kamogawa 2010 (in Japanese).

14. Amano M, Ito K, Ito R. Feminism in Japan 12. Tokyo: Iwanami Publishing, 2009.

15. Moore L, Gillette D, Nakamura Y. King, Warrior, Magician, Lover. Japan Times, 1993.

16. Waki J. Families Caring the Aged-Toward Development of Empowerment. Tokyo: Kawashima Publishing, 1998.

17. Smale B, Dupuis SL. Caregivers of persons with dementia: Roles, experiences, supports and coping. Ontario Dementia Caregiver Needs Project. Available from: https://uwaterloo. $\mathrm{ca} /$ murray-alzheimer-research-and-education-program/sites/ ca.murray-alzheimer-research-and-education-program/files/ uploads/files/InTheirOwnVoices-LiteratureReview.pdf [accessed 14 February 2013].

18. Matsuura T. The actual situation of the care by a working person. Nissay Basic Res. Center 2013; 1: 2-28.

19. Morimoto T, Schreiner AS, Asano H. Caregiver burden and health-related quality of life among Japanese stroke caregivers. Age Ageing 2003; 32: 218-223 (in Japanese, abstract in English). [Medline] [CrossRef]

20. Lynn MR. Determination and quantification of content validity. Nurs Res 1986; 35: 382-385. [Medline] [CrossRef]

21. Murakami N. Making Method of the Psychology Scale. Kyoto: Kitaoji Publishing, 2013.

22. Streiner DL. Health Measurement Scales: A Practical Guide to their Development and Use. Oxford: Oxford University Press, 2008.

23. Mizota K, Murata S, Horie J, et al. Relationship between subjective economic conditions and QOL in elderly female residents of the community. Japan Society of Health Promotion 2010; 12: 9-15 (in Japanese, abstract in English).

24. Arai Y, Kudo K, Hosokawa T, et al. Reliability and validity of the Japanese version of the Zarit Caregiver Burden interview. Psychiatry Clin Neurosci 1997; 51: 281-287 (in Japanese, abstract in English). [Medline] [CrossRef]

25. Zung WWK, Fukuda K, Kobayashi S. Zung Self-rating Depression Scale. Kyoto: Sankyo Publishing, 1983.

26. Mimura C, Griffiths P. A Japanese version of the Rosenberg Self-Esteem Scale: translation and equivalence assessment. J Psychosom Res 2007; 62: 589-594 (in Japanese, abstract in English). [Medline] [CrossRef]

27. Rosenberg M. Society and Adolescent Self-Image. New Jersey: Princeton University Press, 1965.

28. Pearlin LI, Mullan JT, Semple SJ, et al. Caregiving and the stress process: an overview of concepts and their measures. Gerontologist 1990; 30: 583-594. [Medline] [CrossRef]

29. The Ministry of Welfare Kaigo index and the level of independent living of bedridden or demented elderly 2006. Available from: http://www8.ocn.ne.jp/ halfboil/criteria/tab-x5.html [accessed 16 September 2014].

30. Kazue N, Kawano A, Kanaya Y. What care-related murder cases tell us: Issues of supporting family caregivers. Journal of Academy of Home Care. 2010; 14: 95-103 (in Japanese, abstract in English).

31. Yuhara E. What care-related murder cases tell us: Issues of supporting family caregivers Nihon Fukushi University 2011; 125: 41-65 (in Japanese, abstract in English).

32. Kim J. Factors and gender difference in the coping style of caregivers for the frail elderly at home: Based on the survey in Seoul City. Japan Society of Family Society 2001; 13: 73-84 (in Japanese, abstract in English). [CrossRef]

33. Razarus RS, Hayashi S. Measuring Stress to Predict Health Outcome. Tokyo: Seiwa Publishing, 1990.

34. Nishio M, Ogomori K, Ono M, et al. Development of the coping scale for home care of male caregivers of dementia. Bio Medical Fuzzy System 2014; 16: 15-21 (in Japanese, abstract in English).

35. Nakano M. Multivariate Statistical Analysis. Hyogo: Helicity Publishing, 2009.

36. Ministry of Health Labour and Welfare. 2010/Comprehensive Survey of Living Conditions. Available from: http://www. mhlw.go.jp/. [accessed 12 July 2014].

37. Kumagai F. Japanese Family and Regionality. Tokyo: Minerva Publishing, 1997.

38. Scott KE. Dementia caregivers' perspectives regarding the effectiveness of support group involvement. (Order No. 1536619, Western Carolina University). ProQuest Dissertations and Theses 2013; Retrieved from http://search.proquest. com/docview/1355174663? accountid=14500. (1355174663).

39. Czaja SJ, Gitlin LN, Schulz R, et al. Development of the risk appraisal measure: a brief screen to identify risk areas and guide interventions for dementia caregivers. J Am Geriatr Soc 2009; 57: 1064-1072. [Medline] [CrossRef]

40. Ministry of Internal Affairs and Communications Employment Status Survey. Available from: www.stat.go.jp/data/shugyi.2007. [accessed 10 September 2014]. 